\title{
Impact of chronic kidney disease and anemia on health-related quality of life and work productivity: analysis of multinational real-world data
}

Heleen van Haalen ${ }^{1}$, James Jackson ${ }^{2 *}$, Bruce Spinowitz ${ }^{3}$, Gary Milligan² and Rebecca Moon ${ }^{2}$

\begin{abstract}
Background: Reductions in health-related quality of life (HRQoL) in patients with chronic kidney disease (CKD) are thought to be exacerbated by the low hemoglobin ( $\mathrm{Hb}$ ) levels that define anemia, a common complication of CKD. The current analysis evaluated the impact of anemia on HRQoL and work productivity in patients with non-dialysis dependent and dialysis-dependent CKD using real-world data.

Methods: Data were collected in France, Germany, Italy, Spain, the UK, the USA and China in 2012-2018 in the Adelphi Real World Disease Specific Programme ${ }^{T M}$ for CKD, a large, cross-sectional, survey of physicians and their patients. Patients completed three patient-reported outcomes (PRO) instruments: the EuroQol 5-Dimension 3-level (EQ-5D-3 L), the Kidney Disease Quality of Life (KDQOL-36) instrument and the Work Productivity and Activity Impairment questionnaire. PROs were assessed by CKD stage and $\mathrm{Hb}$ levels, and regression analyses were performed with CKD stage and $\mathrm{Hb}$ level as independent variables and PROs as outcome variables, while adjusting for age, sex, CKD stage, comorbidities and cardiovascular risk.

Results: Overall, 5276 patients participated in the survey, including 28\% stage 4 and $36 \%$ dialysis patients. Patients with lower $\mathrm{Hb}$ levels more often reported problems/issues on all EQ-5D-3 L domains $(p<0.0001)$. Regression analyses showed significant associations between lower $\mathrm{Hb}$ levels and the probability of low $(<0.8)$ EQ-5D-3 L utility scores $(p<0.0001)$ and low visual analog scale scores $(p<0.05)$, indicating poorer health status. Associations were seen even when adjusting for CKD stage and other potential confounding factors. Significant associations were observed between Hb level and the 12-Item Short-Form Health Survey (SF-12) Physical Component Summary, SF-12 Mental Component Summary and the three KDQOL-36 subscales (all $p<0.0001$ ), and were confirmed using linear regression analyses adjusting for CKD stage and other potential confounders. Numerically greater work productivity losses and greater activity impairment were observed with lower $\mathrm{Hb}$ levels.
\end{abstract}

Conclusions: Lower Hb levels worsen the impact of CKD on HRQoL, and are associated with lower work productivity in patients with CKD. Assessment and treatment of anemia should be recognized as a key component of integral CKD management throughout all stages of the disease.

Keywords: Anemia, Chronic kidney disease, EQ-5D-3 L, Health-related quality of life, KDQOL-36, Patient-reported outcomes, Real-world

\footnotetext{
* Correspondence: james.jackson@adelphigroup.com

${ }^{2}$ Adelphi Real World, Bollington, UK

Full list of author information is available at the end of the article
}

C C The Author(s). 2020 Open Access This article is licensed under a Creative Commons Attribution 4.0 International License, which permits use, sharing, adaptation, distribution and reproduction in any medium or format, as long as you give appropriate credit to the original author(s) and the source, provide a link to the Creative Commons licence, and indicate if changes were made. The images or other third party material in this article are included in the article's Creative Commons licence, unless indicated otherwise in a credit line to the material. If material is not included in the article's Creative Commons licence and your intended use is not permitted by statutory regulation or exceeds the permitted use, you will need to obtain permission directly from the copyright holder. To view a copy of this licence, visit http://creativecommons.org/licenses/by/4.0/ The Creative Commons Public Domain Dedication waiver (http://creativecommons.org/publicdomain/zero/1.0/) applies to the data made available in this article, unless otherwise stated in a credit line to the data. 


\section{Background}

Chronic kidney disease (CKD) is a progressive condition defined by the presence of kidney damage and decreased level of kidney function, most commonly expressed in terms of estimated glomerular filtration rate (eGFR). CKD has a global prevalence of $11-13 \%$ [1], with estimates ranging from 3.9 to $15.3 \%$, depending on geographical region. The lowest estimates have been reported for Europe and the highest for China [2-4]. In 2015, it was estimated that more than 20 million people in the USA had CKD, with the majority having stage 3 disease, and only a small proportion at stage 4 or 5 [5].

Anemia, a decrease in the hemoglobin ( $\mathrm{Hb})$ carried within red blood cells, is a common complication of CKD and is associated with debilitating symptoms, including fatigue, weakness, shortness of breath, dizziness, headaches and depression [6, 7]. Anemia has been defined as $\mathrm{Hb}<12 \mathrm{~g} / \mathrm{dL}$ in women and $<13 \mathrm{~g} / \mathrm{dL}$ in men [8]. Anemia in CKD is predominantly caused by a relative deficiency of erythropoietin, a hormone produced in adults primarily by the kidneys [9], although shortened red blood cell half-life and functional iron deficiency also contribute to the anemia of CKD [10]. In patients with CKD, anemia is also known to be associated with increased cardiac output, development of left ventricular hypertrophy, angina and congestive heart failure, which in turn are associated with increased morbidity and mortality [11-16]. Analysis of data from the US National Health and Nutrition Examination Survey indicated the proportion of CKD patients with anemia, using the Kidney Disease Improving Global Outcomes definition, was $15.4 \%$; double that in the general population (7.6\%), increasing from $8.4 \%$ at stage 1 to $53.4 \%$ at stage 5 [17]. In addition, several other studies have shown that mean $\mathrm{Hb}$ levels decline with deteriorating kidney function $[8,18]$.

Health-related quality of life (HRQoL) is known to be reduced in patients with CKD, and the presence of anemia appears to be associated with exacerbation of HRQoL impairment [19-22]. However, the incidence of anemia increases with deteriorating kidney function, as do other complications of CKD. It can therefore be very difficult to separate the impact of anemia on HRQoL from the impact of other factors using observational data, although data from large patient cohorts with multiple variables can aid understanding of how patients are affected and provide new insights. Moreover, there are few reports of analysis of data from large cohorts of patients across various geographical areas, using a disease-specific instrument to assess HRQoL. The objective of the current survey was to evaluate the impact of anemia on HRQoL in patients with CKD at varying stages of disease using real-world data from different geographical locations.

\section{Methods \\ Survey design and data collection}

Data were collected in Europe (France, Germany, Spain, Italy, the UK), the USA and China during three periods between June 2012 and February 2018, using the Adelphi Real World Disease Specific Programme ${ }^{\text {тм }}$ (DSP) for CKD. DSPs are large, real-world, cross-sectional, multicountry surveys of physicians and their consulting patients in clinical practice [23]; a diagram describing the study design can be found in Additional file 3: Fig. 1.

Physicians were identified from publicly available lists and invited to participate in the DSP following completion of a short screening questionnaire, if they met the following eligibility criteria:

- Were nephrologists, endocrinologists, cardiologists, hematologists or primary care physicians.

- Were actively involved in managing the treatment of patients with CKD.

- In a typical month, saw a specified minimum number of patients with different stages of CKD (the required number varied between data collection periods and depended on their specialty).

Participating physicians were asked to complete a Patient Record Form (PRF) for twelve patients with CKD stage $3 a$ or above, with a specified number of patients at each stage of CKD (the numbers required at each stage varied depending on the data collection period and the physician's specialty). EGFR was used for both diagnosis and staging of CKD, with eGFR $\geq 90,60-89,45-59,30-44,15-29$ and $<15 \mathrm{ml} / \mathrm{min} / 1.73 \mathrm{~m} 2$ representing stages 1,2 , 3a, $3 \mathrm{~b}, 4$ and 5, respectively [8]. PRFs were completed for consecutively consulting patients at each stage of CKD until the quota of patients for that stage had been reached. Information recorded in the PRF included demographics; disease characteristics and history; current Hb level; concomitant conditions; current treatment and treatment history. Patients for whom a PRF was completed were also invited to complete a patient self-completion form (PSC), which included complementary information on CKD history to that recorded on the PRF, as well as a number of well-established patient-reported outcomes (PRO) instruments.

Data were collected according to market research guidelines; hence, no source validation was possible or required. Patient and physician identities were not known to the research team; no identifiers were recorded for the patients, and PRFs and PSCs for 
each patient were linked by unique numeric codes pre-printed on the forms.

\section{PRO questionnaires}

HRQoL was assessed using the generic EuroQol 5Dimension 3-level (EQ-5D-3 L) measure of health status and the disease-specific Kidney Disease Quality of Life (KDQOL-36) instrument. Productivity was also assessed using the Work Productivity and Activity Impairment (WPAI) questionnaire.

The EQ-5D-3 L is a generic instrument often used routinely in healthcare systems to assess patient health status before and after an intervention [24]. It comprises 5 individual items and a $20 \mathrm{~cm}$ vertical visual analog scale (VAS) $[25,26]$. The individual items ask the respondent to indicate the level of problems related to mobility, self-care, and usual activities (e.g. work, study, housework, family or leisure activities), and the severity of pain/discomfort and anxiety/depression experienced (if any). Each item provides a score ranging from 1 to 3; a single health utility index score is generated using a country-specific algorithm that provides a number, with 1 indicating perfect health, 0 death and $<0$ worse than death [27]. Patients indicate their general health status on the day that they complete the EQ-5D-3 $\mathrm{L}$ by drawing a line on the VAS to provide a score ranging from 0 (worst imaginable health state) to 100 (best imaginable health state).

The KDQOL-36 is one of the most-commonly used disease-specific instruments in studies showing HRQoL impairment in CKD [28-31]. It comprises 36 items, including the generic 12-Item Short-Form Health Survey (SF-12) to provide 2 summary scores assessing impact on the physical and mental dimensions of HRQoL, and a further 24 items to provide 3 disease-specific subscales [32, 33]:

- The SF-12 Physical Component Summary (PCS) is calculated from all 12 items in the SF-12.

- The SF-12 Mental Component Summary (MCS) is calculated from all 12 items in the SF-12.

- The symptoms and problems with kidney disease subscale is calculated from 12 items each describing a symptom of kidney disease. Patients are asked to what extent they were bothered by each of these during the past 4 weeks, with 5 response options ranging from "Not at all bothered" to "Extremely bothered."

- The effects of kidney disease on daily life subscale is calculated from 8 items describing ways in which kidney disease can impact a range of issues, such as a patient's ability to work around the house, and their personal appearance. Patients are asked to what extent they are bothered by each of these, with 5 response options ranging from "Not at all bothered" to "Extremely bothered".
- The burden of kidney disease subscale is calculated from 4 statements related to the impact of kidney disease on the patient and their family. Patients indicate their agreement with the statements by choosing from 5 response options ranging from "Definitely true" to "Definitely false".

The SF-12 PCS and MCS are calculated as the sum of scores following conversion into standardized values. The disease-specific subscales are scored by transforming all items to a score in the range 0 to 100 and averaging across the items. Higher scores indicate better HRQoL in all cases.

The WPAI is an instrument to assess the impact of disease on work productivity and daily activities over the past 7 days. Its use has been completed by patients in a large number of studies and a wide range of disease areas [34]; as it is not disease-specific, it can be used to compare productivity impact across diseases. The WPAI comprises 6 items and results in the generation of 4 scores, each expressed as a percentage of work time missed or a percentage impairment [35]:

- Absenteeism (work time missed due to impairment): calculated as hours missed as a percentage of total work hours using: patient-reported hours missed during the 7-day recall period / (patient-reported hours worked during the 7-day recall period + patient-reported hours missed during the 7-day recall period) $\times 100$ );

- Presenteeism (ability to function at work while being impaired): calculated as a percentage using: patientreported impact of CKD on productivity at work during the 7-day recall period recorded on a scale of 0 (no impact) to 10 (prevented me from working) $\times 10$;

- Overall work impairment: calculated as a percentage using: patient-reported hours worked, patientreported hours missed and patient-reported impact of CKD on productivity during the 7-day recall period, applying an algorithm described on the WPAI website [36]; and

- Total activity impairment: calculated as a percentage using: patient-reported impact of CKD on productivity in regular unpaid activities during the 7-day recall period recorded on a scale of 0 (no impact) to 10 (prevented activities) $\times 10$.

\section{Analysis}

Means and standard deviations were calculated for continuous variables, and frequency counts and percentages for categorical variables. Descriptive analyses were performed for the total survey population and stratified by $\mathrm{Hb}$ level, geographical region, and CKD stage. For the generic EQ-5D-3 L, Hb levels of $<8 \mathrm{~g} / \mathrm{dL}, 8-<10 \mathrm{~g} / \mathrm{dL}$, 
$10-12 \mathrm{~g} / \mathrm{dL}$, and $>12 \mathrm{~g} / \mathrm{dL}$ were used; for the KDQOL36 and WPAI, Hb levels of $<10 \mathrm{~g} / \mathrm{dL}, 10-12 \mathrm{~g} / \mathrm{dL}$, and $>$ $12 \mathrm{~g} / \mathrm{dL}$ were used. CKD stages were $3 \mathrm{a}$ non-dialysis dependent (NDD), 3b NDD, 4 NDD, 5 NDD, and dialysis-dependent (DD).

The non-parametric Spearman's rank correlation test was used to assess the correlation of $\mathrm{Hb}$ level with EQ5D-3 L utility index and domains, EQ-5D-3 L VAS, SF12 PCS, SF-12 MCS scores and the three subscales from the KDQOL-36. To adjust for potential confounding, linear regression analyses were performed on EQ-5D-3 L VAS, SF-12 PCS, SF-12 MCS and the three subscales from the KDQOL-36 as the outcome variables; independent variables included were $\mathrm{Hb}$ level (continuous), CKD stage, $\mathrm{Hb}$ and CKD stage interacted, sex, common comorbidities (diabetes, heart failure, stroke) and cardiovascular risk. Logistic regression analysis was performed with the same independent variables and EQ-5D-3 L utility index score (classified as $\geq 0.8$ and $<0.8$ ) as the outcome variable. Exploratory analyses compared KDQOL-36 and WPAI scores for patients with $\mathrm{Hb}<8$ $\mathrm{g} / \mathrm{dL}$ with those for patients with higher Hb levels.

Patients who had completed a PSC, and for whom current CKD stage and $\mathrm{Hb}$ level were available were included in the analysis. Patients with no Hb level reported were included in the descriptive analysis of demographics and disease characteristics, but excluded from all other analyses. Missing data were not imputed but remained missing; therefore, the base of patients for analysis could vary between variables, and is reported for each analysis. All descriptive and exploratory analyses were conducted using IBM SPSS Data Collection Survey Reporter version 6 or later and all statistical testing was conducted in Stata v15.1 [37].

\section{Results}

\section{Participants}

Overall, 770 physicians participated, providing data for a total of 5276 patients, 2622 from Europe, 1933 from the USA and 721 from China. Sixty-four percent of patients were NDD and $36 \%$ of patients were DD. In addition, $28 \%$ of patients were in CKD stage 4, 19\% were in CKD stage $3 \mathrm{~b}$ and $16 \%$ were in CKD stage 3a. Only $1 \%$ of patients were in CKD stage 5 while NDD. The mean $\mathrm{Hb}$ level within the cohort was $11.5 \mathrm{~g} / \mathrm{dL}$ (standard deviation [SD] $1.9 \mathrm{~g} / \mathrm{dL}$ ) and $13 \%$ of patients had a $\mathrm{Hb}$ level $<10 \mathrm{~g} / \mathrm{dL}$. The range of measured $\mathrm{Hb}$ values in the data was 3.4 to $20.5 \mathrm{~g} / \mathrm{dL}$. The distribution of $\mathrm{Hb}$ values is shown in Additional file 3: Fig. 2. Hypertension was identified as the underlying cause of CKD in 59\% of patients, followed by Type 2 Diabetes (39\% of patients; Table 1). However, multiple causes of CKD were registered for some patients.

Patient demographics were generally similar across geographic regions, although body mass index (BMI) was numerically higher in patients from the USA and lower in patients from China compared with those from Europe (Table 1). The proportion of patients currently employed was numerically higher in the USA and lower in China compared to patients in Europe, and the proportion of retired patients was numerically higher in China and lower in the USA compared to patients in Europe (Table 1); this might reflect geographical differences in the typical age for retirement. Patients' ethnic origin can be found in Table 1 .

Across countries, there were minor differences in the proportion of patients with low $\mathrm{Hb}$, with the proportion of patients with $\mathrm{Hb}<10 \mathrm{~g} / \mathrm{dL}$ being numerically higher in China compared to the USA and Europe. Glomerulonephritis was reported as the underlying cause of CKD in $47 \%$ of Chinese patients compared to $8 \%$ of patients in the USA or $15 \%$ of patients in Europe; however, Chinese patients appeared to have fewer comorbidities (Table $1)$.

Different types of anemia treatments currently used by participating patients were recorded across regions. However, only data from 2015 and 2018 on anemia treatment types were available (Table 1).

\section{Health status assessed with EQ-5D-3 L}

An association was observed between EQ-5D-3 L domain scores and $\mathrm{Hb}$ levels; all EQ-5D-3 L domains showed significantly greater problems/issues with lower $\mathrm{Hb}$ levels $(p<0.0001$ all domains; Table 2).

A trend was observed for lower EQ-5D-3 L utility index and VAS scores, indicating poorer health status, to be reported at more advanced CKD stages and by patients with lower $\mathrm{Hb}$ levels across all CKD stages (Fig. 1), although patient numbers at more advanced CKD stage and lower $\mathrm{Hb}$ levels were low. Significant associations of $\mathrm{Hb}$ level with EQ-5D-3 L utility index score and VAS score were shown using Spearman's correlations $(p<0.0001)$ and confirmed using logistic regression (EQ-5D-3 L utility index ( $\geq 0.8): p<0.0001$; Fig. 2a) and linear regression (EQ-5D-3 L VAS: $p<0.0001$; Fig. 2b). Regression analyses also confirmed associations of EQ-5D-3 L utility index and VAS scores with $\mathrm{Hb}$ level and CKD stage (Fig. $2 \mathrm{c}$ and $\mathrm{d}$; $p$-values all four analyses $<0.0001)$. The associations of the HRQoL indices with $\mathrm{Hb}$ level were consistently stronger in NDD CKD patients than in DD CKD patients.

The association of lower EQ-5D-3 L utility index and VAS scores with lower $\mathrm{Hb}$ levels and more advanced CKD stages was observed across geographic regions (data shown in Appendix - Additional file 1: Table 1). At any $\mathrm{Hb}$ level, EQ-5D-3 L utility index scores were generally numerically higher in patients from the USA than those from Europe or China in both NDD and DD patients, while VAS scores were also typically numerically higher in 
Table 1 Patient demographics and disease characteristics

\begin{tabular}{|c|c|c|c|c|}
\hline & $\begin{array}{l}\text { All patients } \\
N=5276\end{array}$ & $\begin{array}{l}\text { Europe } \\
N=2622\end{array}$ & $\begin{array}{l}\text { USA } \\
N=1933\end{array}$ & $\begin{array}{l}\text { China } \\
N=721\end{array}$ \\
\hline \multicolumn{5}{|l|}{$\mathrm{Age}^{\mathrm{a}}$, years } \\
\hline Mean (SD) & $60.9(14.3)$ & $62.5(15.1)$ & $59.8(14.2)$ & $58.3(10.1)$ \\
\hline Median & 62 & 65 & 61 & 59 \\
\hline Min, Max & 18,89 & 18,89 & 18,89 & 22,89 \\
\hline > 90 years old, $\mathrm{n}(\%)$ & $42(0.8 \%)$ & $25(1.0 \%)$ & 17 (0.9\%) & $0(0.0 \%)$ \\
\hline \multicolumn{5}{|l|}{ Sex, n (\%) } \\
\hline Female & $2259(43 \%)$ & $1067(41 \%)$ & $869(45 \%)$ & $323(45 \%)$ \\
\hline Male & 3017 (57\%) & 1555 (59\%) & $1064(55 \%)$ & $398(55 \%)$ \\
\hline \multicolumn{5}{|l|}{$\mathrm{BMI}, \mathrm{kg} / \mathrm{m}^{2}$} \\
\hline Mean (SD) & $26.9(5.8)$ & $26.5(4.9)$ & $29.2(6.4)$ & $22.4(3.2)$ \\
\hline Median & 25.9 & 25.8 & 28.1 & 22.0 \\
\hline Min, Max & 13,74 & 15,74 & 13,70 & 14,47 \\
\hline Unknown, n (\%) & $162(3.1 \%)$ & $94(3.6 \%)$ & $61(3.2 \%)$ & $7(1.0 \%)$ \\
\hline \multicolumn{5}{|l|}{ Ethnic origin, n (\%) } \\
\hline White/Caucasian & $2991(57 \%)$ & 1928 (74\%) & $1063(55 \%)$ & $0(0 \%)$ \\
\hline Chinese & $754(14 \%)$ & $2(0 \%)$ & $37(2 \%)$ & $715(100 \%)$ \\
\hline African American & $517(10 \%)$ & $5(0 \%)$ & $512(27 \%)$ & $0(0 \%)$ \\
\hline Hispanic/Latino & $248(5 \%)$ & $51(2 \%)$ & $197(10 \%)$ & $0(0 \%)$ \\
\hline North/Western/Middle EU & $437(8 \%)$ & 437 (17\%) & $0(0 \%)$ & $0(0 \%)$ \\
\hline Asian - other & $76(1 \%)$ & $12(0 \%)$ & $64(3 \%)$ & $0(0 \%)$ \\
\hline Other ${ }^{b}$ & $241(5 \%)$ & $181(7 \%)$ & $59(3 \%)$ & $1(0 \%)$ \\
\hline Unknown & $12(<1 \%)$ & $6(<1 \%)$ & $1(<1 \%)$ & $5(<1 \%)$ \\
\hline \multicolumn{5}{|l|}{ Employment status, n (\%) } \\
\hline Employed $^{c}$ & $1265(24 \%)$ & $593(23 \%)$ & $574(30 \%)$ & $98(14 \%)$ \\
\hline Retired & 2555 (49\%) & $1356(52 \%)$ & 719 (37\%) & $480(67 \%)$ \\
\hline Other $^{d}$ & $1287(24 \%)$ & $607(23 \%)$ & $558(29 \%)$ & $122(17 \%)$ \\
\hline Unknown & $169(3 \%)$ & $66(3 \%)$ & $82(4 \%)$ & $21(3 \%)$ \\
\hline \multicolumn{5}{|l|}{ Current $\mathrm{Hb}$ level, g/dL } \\
\hline Mean (SD) & $11.5(1.9)$ & $11.6(1.8)$ & $11.8(1.9)$ & $10.8(1.7)$ \\
\hline Median & 11.5 & 11.6 & 11.5 & 11.0 \\
\hline Min, Max & 3,21 & 3,19 & 6,21 & 4,19 \\
\hline Unknown, n (\%) & $485(9.2 \%)$ & $214(8.2 \%)$ & $247(12.8 \%)$ & $24(3.3 \%)$ \\
\hline \multicolumn{5}{|l|}{ Current Hb level, n (\%) } \\
\hline $\mathrm{Hb}<8 \mathrm{~g} / \mathrm{dL}$ & $141(3 \%)$ & $95(4 \%)$ & $17(1 \%)$ & $29(4 \%)$ \\
\hline $\mathrm{Hb} 8-10 \mathrm{~g} / \mathrm{dL}$ & $533(10 \%)$ & $206(8 \%)$ & $197(10 \%)$ & $130(18 \%)$ \\
\hline $\mathrm{Hb} 10-12 \mathrm{~g} / \mathrm{dL}$ & $2464(47 \%)$ & $1216(46 \%)$ & $834(43 \%)$ & $414(57 \%)$ \\
\hline $\mathrm{Hb}>12 \mathrm{~g} / \mathrm{dL}$ & $1653(31 \%)$ & 891 (34\%) & $638(33 \%)$ & $124(17 \%)$ \\
\hline Unknown & $485(9 \%)$ & $214(8 \%)$ & $247(13 \%)$ & $24(3 \%)$ \\
\hline \multicolumn{5}{|l|}{ Current CKD stage, n (\%) } \\
\hline Stage 3a NDD & $821(16 \%)$ & 397 (15\%) & $274(14 \%)$ & $150(21 \%)$ \\
\hline Stage 3b NDD & $983(19 \%)$ & $523(20 \%)$ & $310(16 \%)$ & $150(21 \%)$ \\
\hline Stage 4 NDD & $1492(28 \%)$ & 753 (29\%) & $462(24 \%)$ & 277 (38\%) \\
\hline Stage 5 NDD & $57(1 \%)$ & $31(1 \%)$ & $24(1 \%)$ & $2(0 \%)$ \\
\hline
\end{tabular}


Table 1 Patient demographics and disease characteristics (Continued)

\begin{tabular}{|c|c|c|c|c|}
\hline & $\begin{array}{l}\text { All patients } \\
N=5276\end{array}$ & $\begin{array}{l}\text { Europe } \\
N=2622\end{array}$ & $\begin{array}{l}\text { USA } \\
N=1933\end{array}$ & $\begin{array}{l}\text { China } \\
N=721\end{array}$ \\
\hline $\mathrm{DD}$ & $1923(36 \%)$ & $918(35 \%)$ & $863(45 \%)$ & $142(20 \%)$ \\
\hline \multicolumn{5}{|l|}{ Underlying cause of $C K D^{\mathrm{e}}, \mathrm{n}(\%)$} \\
\hline Hypertension & $3070(59 \%)$ & $1417(54 \%)$ & $1285(67 \%)$ & $368(51 \%)$ \\
\hline Type 2 Diabetes & $2034(39 \%)$ & $928(36 \%)$ & $812(42 \%)$ & $294(41 \%)$ \\
\hline Cardiovascular disease & $888(17 \%)$ & $454(17 \%)$ & $359(19 \%)$ & $75(10 \%)$ \\
\hline Glomerulonephritis & $883(17 \%)$ & $391(15 \%)$ & $156(8 \%)$ & $336(47 \%)$ \\
\hline Unknown & $34(1 \%)$ & $14(1 \%)$ & $17(1 \%)$ & $3(0 \%)$ \\
\hline \multicolumn{5}{|l|}{ Comorbid conditions ${ }^{f}, \mathrm{n}(\%)$} \\
\hline Hypertension & $2350(78 \%)$ & $1044(82 \%)$ & $857(84 \%)$ & 449 (62\%) \\
\hline Type 2 diabetes & $1199(40 \%)$ & $430(34 \%)$ & $497(49 \%)$ & $272(38 \%)$ \\
\hline Dyslipidemia & 877 (29\%) & $335(26 \%)$ & $449(44 \%)$ & $93(13 \%)$ \\
\hline Coronary heart disease & $536(18 \%)$ & $206(16 \%)$ & 196 (19\%) & $134(19 \%)$ \\
\hline Depression & $366(12 \%)$ & $151(12 \%)$ & $175(17 \%)$ & $40(6 \%)$ \\
\hline Anxiety & $321(11 \%)$ & $152(12 \%)$ & $144(14 \%)$ & $25(3 \%)$ \\
\hline Atherosclerosis & $319(11 \%)$ & $162(13 \%)$ & $100(10 \%)$ & $57(8 \%)$ \\
\hline No comorbidities & $400(13 \%)$ & $131(10 \%)$ & $35(3 \%)$ & $234(32 \%)$ \\
\hline Unknown & $2260(43 \%)$ & $1350(51 \%)$ & $910(47 \%)$ & $0(0 \%)$ \\
\hline Type of anemia treatment currently received ${ }^{9}, \mathrm{n}(\%)$ & $N=1209$ & $N=548$ & $N=384$ & $N=277$ \\
\hline Oral iron only & $315(26 \%)$ & 77 (14\%) & $139(36 \%)$ & $99(36 \%)$ \\
\hline IV iron only & $79(7 \%)$ & $54(10 \%)$ & $14(4 \%)$ & $11(4 \%)$ \\
\hline ESA only & $258(21 \%)$ & $126(23 \%)$ & $101(26 \%)$ & $31(11 \%)$ \\
\hline Both oral iron and ESA & $227(19 \%)$ & $107(19 \%)$ & $33(9 \%)$ & $87(31 \%)$ \\
\hline Both IV iron and ESA & $330(27 \%)$ & $184(34 \%)$ & $97(25 \%)$ & 49 (18\%) \\
\hline \multicolumn{5}{|c|}{ 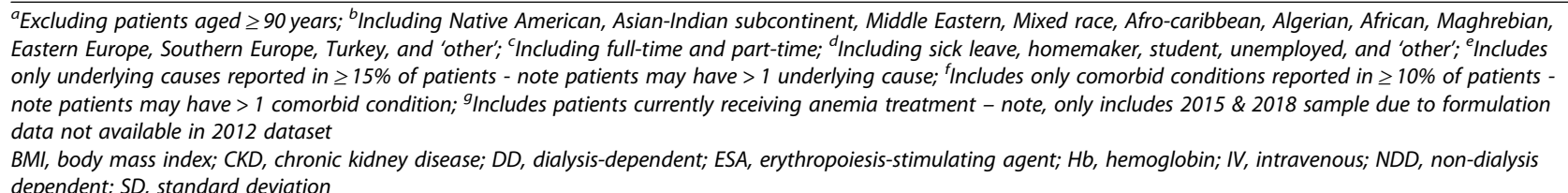 } \\
\hline
\end{tabular}

DD patients from the USA than from other geographic regions.

\section{HRQoL assessed with KDQOL-36}

Numerically lower mean scores, indicating poorer HRQoL, were reported by patients with lower $\mathrm{Hb}$ levels for the KDQOL-36 SF-12 PCS, SF-12 MCS, symptoms and problems with kidney disease subscale, effects of kidney disease on daily life subscale, and burden of kidney disease subscale across all CKD stages, with the exception of stage $3 \mathrm{a}$ (Table 3 ). Using $\mathrm{Hb}$ level groupings of $<10 \mathrm{~g} / \mathrm{dL}, 10-12 \mathrm{~g} / \mathrm{dL}$, and $>12 \mathrm{~g} / \mathrm{dL}$, significant associations of $\mathrm{Hb}$ level with the SF-12 PCS and MCS scores and all three subscales from the KDQOL-36 were shown using Spearman's correlations $(p<0.0001)$. These associations were confirmed using linear regression analysis $(p<0.0001)$, with a stronger association observed in NDD than DD patients (Fig. 3a-e). Linear regression analyses also confirmed associations of SF-12 PCS and MCS scores and all three subscales from the KDQOL-36 with CKD stage $(\mathrm{p}<0.0001$; Fig. $4 \mathrm{a}-\mathrm{e})$. Exploratory analyses did not show incremental decreases of KDQOL-36 scores for patients with $\mathrm{Hb}$ levels $<8 \mathrm{~g} / \mathrm{dL}$ compared with those for patients with $\mathrm{Hb}$ levels of $8-<10 \mathrm{~g} / \mathrm{dL}$.

Mean KDQOL-36 SF-12 PCS and MCS scores were generally numerically higher (indicating better HRQoL) in the USA and lower in China compared to Europe at all stages of CKD, except for SF-12 PCS at stage 5, were patient numbers were very low (data shown in Appendix - Additional file 2: Table 2).

\section{Productivity assessed with WPAI}

Numerically higher mean percentage absenteeism, presenteeism and overall work impairment were reported on the WPAI by patients with lower Hb levels at CKD stages 4 and 5, and for all NDD and DD patients (Table 4). The 
Table 2 EQ-5D-3 L domain scores by Hb level

\begin{tabular}{|c|c|c|c|c|c|c|}
\hline $\begin{array}{l}N \\
n(\%)\end{array}$ & All Hb levels & $\begin{array}{l}\mathrm{Hb} \\
>12 \mathrm{~g} / \mathrm{dL}\end{array}$ & $\begin{array}{l}\mathrm{Hb} \\
10-12 \mathrm{~g} / \mathrm{dL}\end{array}$ & $\begin{array}{l}\mathrm{Hb} \\
8-<10 \mathrm{~g} / \mathrm{dL}\end{array}$ & $\begin{array}{l}\mathrm{Hb} \\
<8 \mathrm{~g} / \mathrm{dL}\end{array}$ & $p$-value ${ }^{a}$ \\
\hline Mobility & 4665 & 1613 & 2387 & 525 & 140 & $P<0.0001$ \\
\hline I have no problems in walking about & $2988(64.1 \%)$ & $1177(73.0 \%)$ & $1453(60.9 \%)$ & $293(55.8 \%)$ & $65(46.4 \%)$ & \\
\hline I have some problems in walking about & $1613(34.6 \%)$ & $429(26.6 \%)$ & $901(37.7 \%)$ & $216(41.1 \%)$ & $67(47.9 \%)$ & \\
\hline I am confined to bed & $64(1.4 \%)$ & $7(0.4 \%)$ & $33(1.4 \%)$ & $16(3.0 \%)$ & $8(5.7 \%)$ & \\
\hline Self-care & 4656 & 1612 & 2381 & 524 & 139 & $P<0.0001$ \\
\hline I have no problems with self-care & $3645(78.3 \%)$ & $1362(84.5 \%)$ & $1824(76.6 \%)$ & $375(71.6 \%)$ & $84(60.4 \%)$ & \\
\hline I have some problems washing or dressing myself & $914(19.6 \%)$ & $234(14.5 \%)$ & $504(21.2 \%)$ & $129(24.6 \%)$ & $47(33.8 \%)$ & \\
\hline I am unable to wash or dress myself & $97(2.1 \%)$ & $16(1.0 \%)$ & $53(2.2 \%)$ & $20(3.8 \%)$ & $8(5.8 \%)$ & \\
\hline Usual activities & 4652 & 1610 & 2379 & 524 & 139 & $P<0.0001$ \\
\hline I have no problems with performing my usual activities & $2544(54.7 \%)$ & $1031(64.0 \%)$ & $1228(51.6 \%)$ & $233(44.5 \%)$ & $52(37.4 \%)$ & \\
\hline I have some problems with performing my usual activities & $1910(41.1 \%)$ & $543(33.7 \%)$ & $1049(44.1 \%)$ & $249(47.5 \%)$ & $69(49.6 \%)$ & \\
\hline I am unable to perform my usual activities & $198(4.3 \%)$ & $36(2.2 \%)$ & $102(4.3 \%)$ & $42(8.0 \%)$ & $18(12.9 \%)$ & \\
\hline Pain/Discomfort & 4653 & 1611 & 2377 & 524 & 141 & $P<0.0001$ \\
\hline I have no pain or discomfort & $1943(41.8 \%)$ & $825(51.2 \%)$ & $899(37.8 \%)$ & $178(34.0 \%)$ & $41(29.1 \%)$ & \\
\hline I have moderate pain or discomfort & $2534(54.5 \%)$ & $744(46.2 \%)$ & $1382(58.1 \%)$ & $313(59.7 \%)$ & $95(67.4 \%)$ & \\
\hline I have extreme pain or discomfort & $176(3.8 \%)$ & $42(2.6 \%)$ & $96(4.0 \%)$ & $33(6.3 \%)$ & $5(3.5 \%)$ & \\
\hline Anxiety/Depression & 4650 & 1611 & 2373 & 526 & 140 & $P<0.0001$ \\
\hline I am not anxious or depressed & $2657(57.1 \%)$ & $1002(62.2 \%)$ & $1294(54.5 \%)$ & $284(54.0 \%)$ & $77(55.0 \%)$ & \\
\hline I am moderately anxious or depressed & 1769 (38.0\%) & $556(34.5 \%)$ & $946(39.9 \%)$ & $210(39.9 \%)$ & $57(40.7 \%)$ & \\
\hline I am extremely anxious or depressed & 224 (4.8\%) & 53 (3.3\%) & 133 (5.6\%) & $32(6.1 \%)$ & $6(4.3 \%)$ & \\
\hline
\end{tabular}

${ }^{a}$ Spearman correlation used to compare findings between patients with different $\mathrm{Hb}$ levels for each domain $\mathrm{Hb}$, hemoglobin

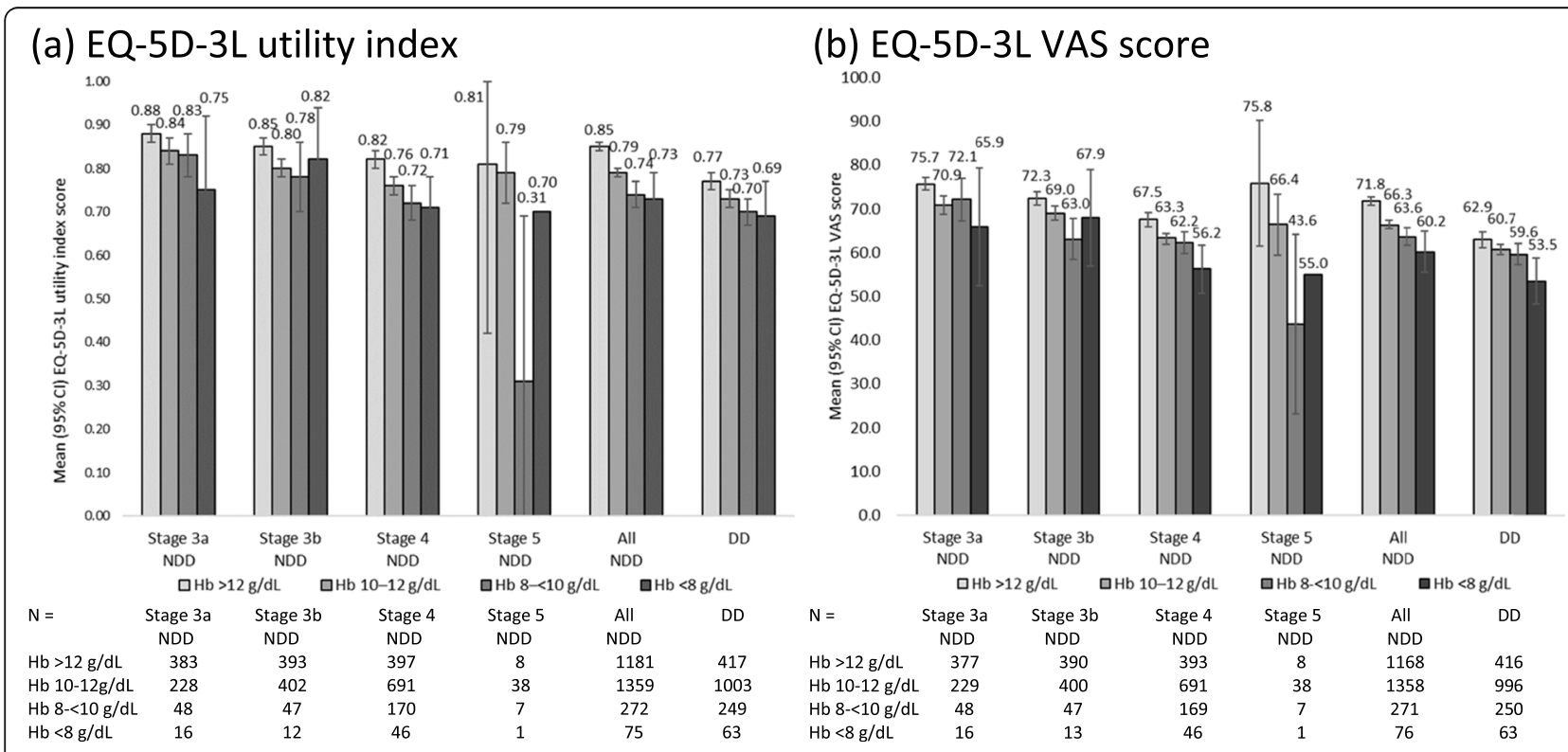

Fig. 1 EQ-5D-3 L by Hb level and CKD stage. Cl, confidence interval; CKD, chronic kidney disease; DD, dialysis-dependent; Hb, hemoglobin; NDD, nondialysis dependent; VAS, visual analog scale 
(a) EQ-5D-3L utility index with $\mathrm{Hb}_{\text {level }}{ }^{\mathrm{b}}$

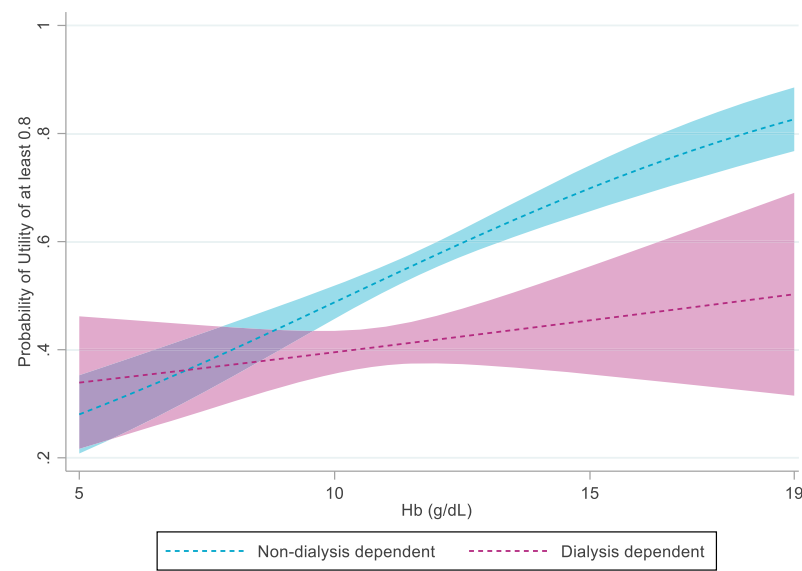

(c) EQ-5D-3L utility index with $\mathrm{Hb}$ level and CKD stage ${ }^{c}$

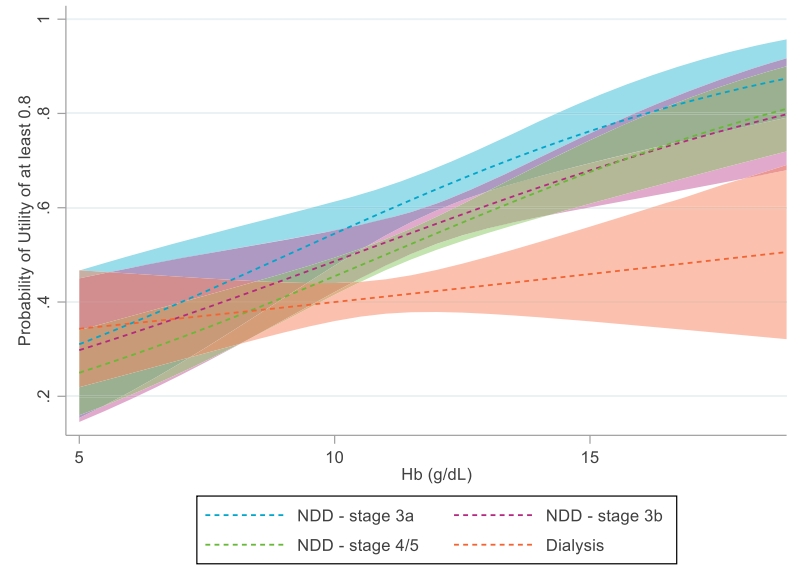

(b) EQ-5D-3L VAS scores with Hb level

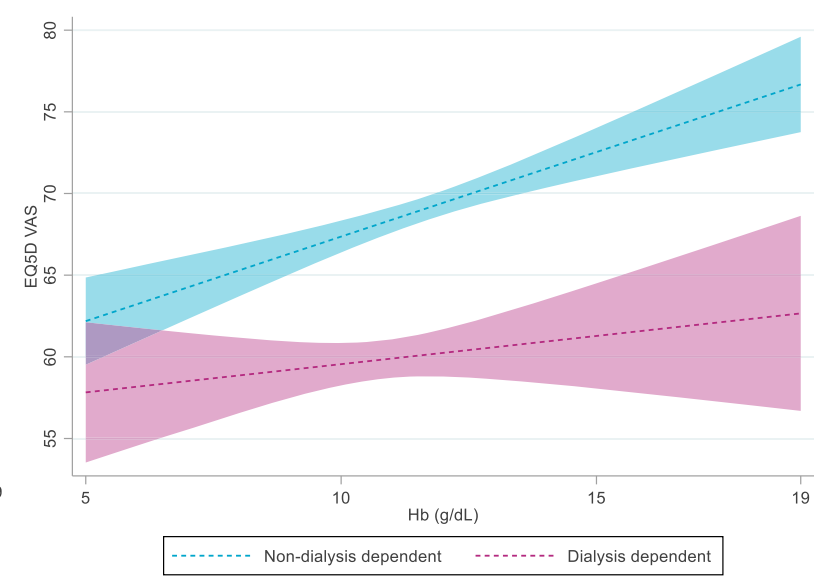

(d) EQ-5D-3L VAS scores with $\mathrm{Hb}$ level and CKD stage ${ }^{c}$

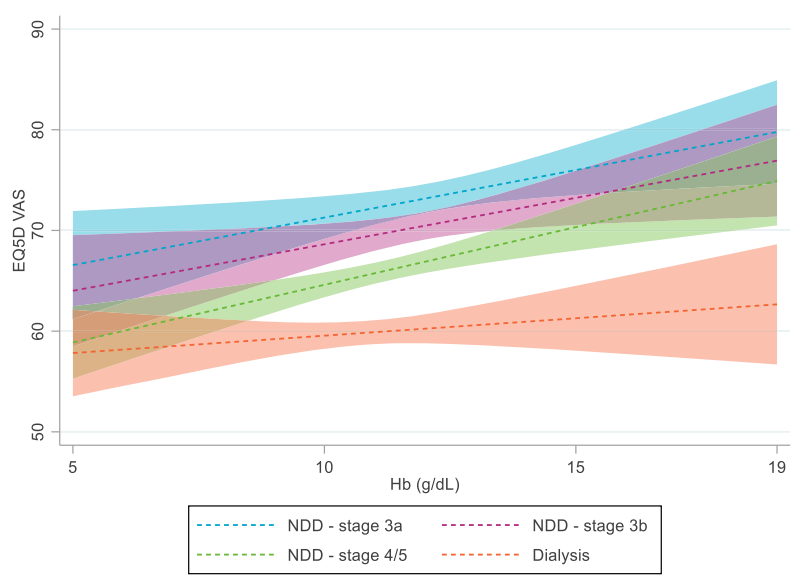

Fig. 2 Regression analyses ${ }^{a}{ }^{a}$ These figures use regression models to show how the outcome changes with changing Hb with all other covariates set

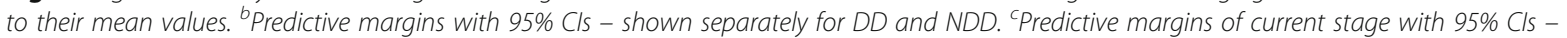
shown separately for each CKD stage. Cl, confidence interval; CKD, chronic kidney disease; Hb, hemoglobin; NDD, non-dialysis dependent; VAS, visual analog scale

relatively small number of patients in employment resulted in low samples for calculation of absenteeism, presenteeism and overall work impairment. Increasing levels of total activity impairment were observed with decreasing $\mathrm{Hb}$ levels at all CKD stages, except for stage 3a (Table 4). Exploratory analyses indicated greater total activity impairment for patients with $\mathrm{Hb}$ levels $<8 \mathrm{~g} / \mathrm{dL}$ compared with those with $\mathrm{Hb}$ levels of $8-<10 \mathrm{~g} / \mathrm{dL}$, but did not show incremental increases in absenteeism, presenteeism, and overall work impairment.

\section{Discussion}

This study evaluated the impact of anemia on HRQoL in patients with CKD at varying stages of disease in a large, geographically diverse patient population. CKD itself markedly reduced HRQoL, and this reduction was exacerbated by anemia. At lower Hb levels, similar (low) HRQoL scores were found across CKD stages. This clearly illustrated the humanistic burden of CKD as the disease advanced, particularly for patients with low $\mathrm{Hb}$ levels. Using a number of statistical approaches, multiple established HRQoL indices and sub scores showed significant correlations with $\mathrm{Hb}$ level. These findings support the idea that $\mathrm{Hb}$ level impacts HRQoL in CKD patients, independent of other factors such as CKD stage and other comorbidities, which were included as covariables in the model. Interestingly, the observed correlations between $\mathrm{Hb}$ level and HRQoL appeared consistently stronger in NDD CKD patients compared with DD CKD patients. In addition, lower Hb levels were found to be associated with greater work productivity losses and total activity impairments, suggesting 


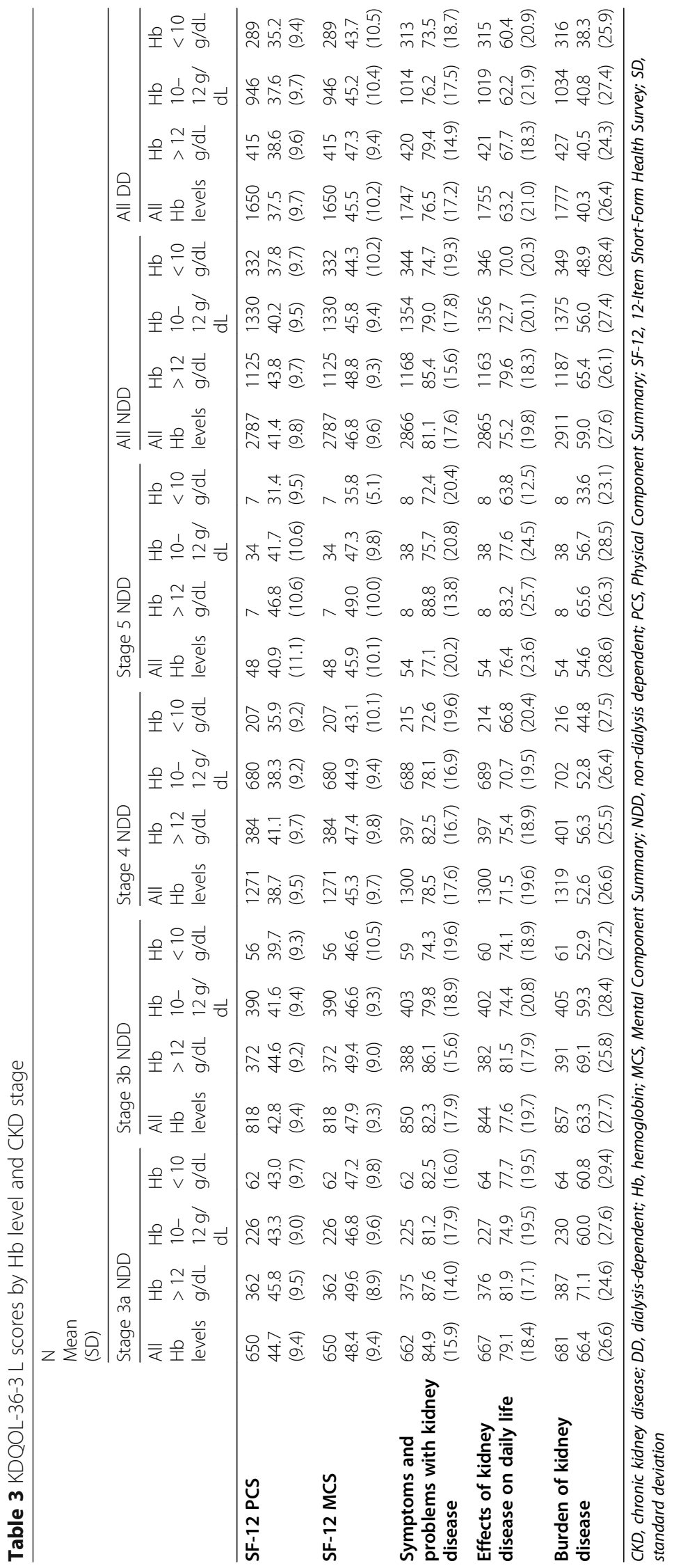


(a) KDQOL-36 SF-12 PCS

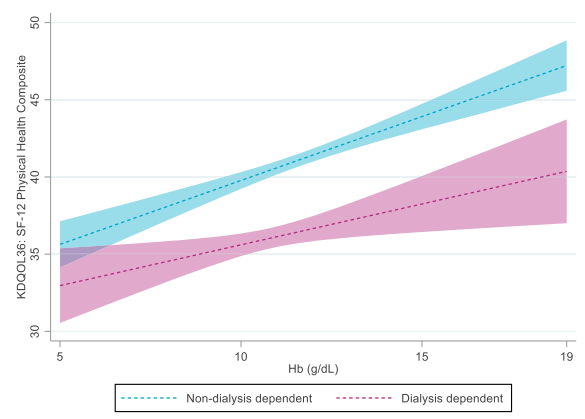

(c) KDQOL-36 symptoms and problems ${ }^{\text {b }}$

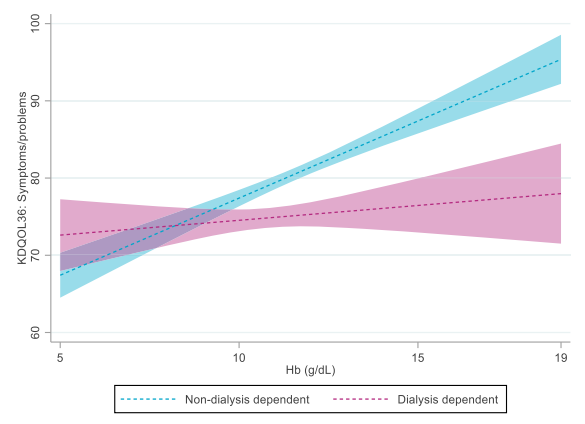

(e) KDQOL-36 burden of kidney disease ${ }^{d}$

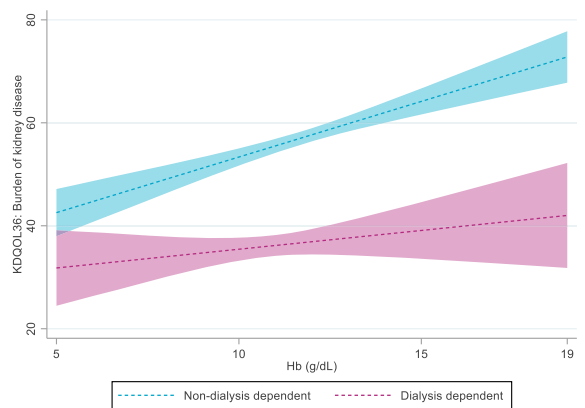

(b) KDQOL-36 SF-12 MCS

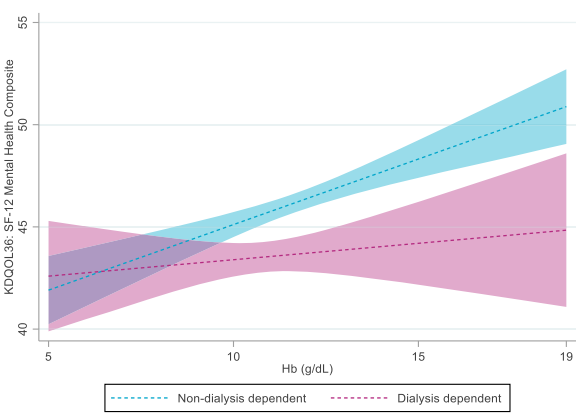

(d) KDQOL-36 effects of kidney disease ${ }^{c}$

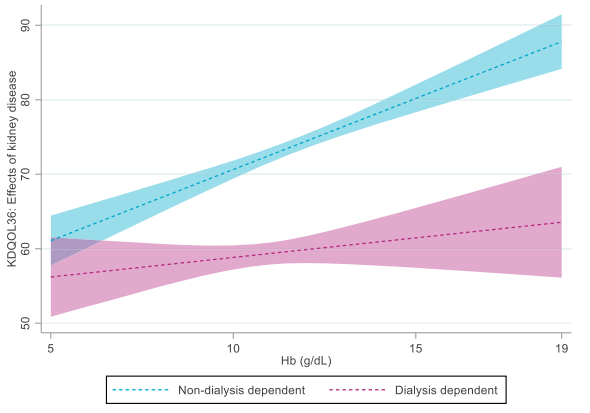

Fig. 3 Regression analyses ${ }^{a}$. ${ }^{a}$ These figures use regression models to show how the outcome changes with changing Hb with all other covariates set to their mean values. Predictive margins with $95 \% \mathrm{Cls}$ are shown separately for DD and NDD ${ }^{b}$ Symptoms and problems with kidney disease subscale. ${ }^{c}$ Effects of kidney disease on daily life subscale. ${ }^{d}$ Burden of kidney disease subscale. $\mathrm{Cl}$, confidence interval; $\mathrm{Hb}$, hemoglobin; NDD, non-dialysis dependent

potential economic consequences, with increased indirect costs related to the presence of anemia.

Due to the generic nature of the EQ-5D-3 L, comparisons can be made between scores observed for this CKD population and those published for the general population in the same countries. Our findings show that patients with CKD not currently requiring dialysis had EQ$5 \mathrm{D}-3 \mathrm{~L}$ utility index scores similar to the general population (0.80-0.94 [27];) if they had $\mathrm{Hb}>12 \mathrm{~g} / \mathrm{dL}$, but those with $\mathrm{Hb}$ levels indicative of more severe anemia had poorer health status than the general population. For patients requiring dialysis, all utility index scores were lower than population norms, with scores decreasing as $\mathrm{Hb}$ level decreased. Compared with population norms for EQ-5D-3 L VAS scores in the relevant countries (72.0-81.6 [27];), VAS scores were lower in this survey for all groups except patients at CKD stages $3 \mathrm{a}$ and $3 \mathrm{~b}$ with $\mathrm{Hb}>12 \mathrm{~g} / \mathrm{dL}$. The small number of patients with CKD stage 5 limited interpretation of data for this group.

Our results were very consistent, given that lower KDQOL-36 SF-12 PCS scores, SF-12 MCS scores and the scores on the three KDQOL-36 subscales were all significantly associated with lower $\mathrm{Hb}$ levels, with regression analyses confirming these associations. The only exception was the lack of an incremental decrement in KDQOL-36 scores at Hb levels $<8 \mathrm{~g} / \mathrm{dL}$ compared to $\mathrm{Hb}$ $10-12 \mathrm{~g} / \mathrm{dL}$ in exploratory analyses, which might be 
(a) KDQOL-36 SF-12 PCS

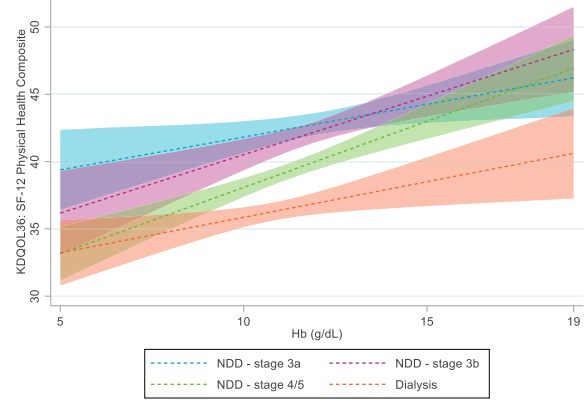

(c) KDQOL-36 symptoms and problems ${ }^{\mathrm{b}}$

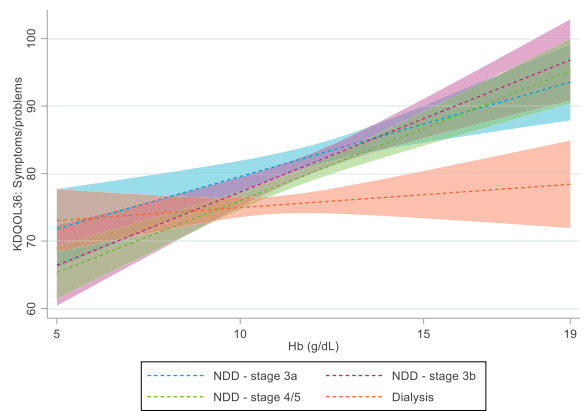

(e) KDQOL-36 burden of kidney disease ${ }^{d}$

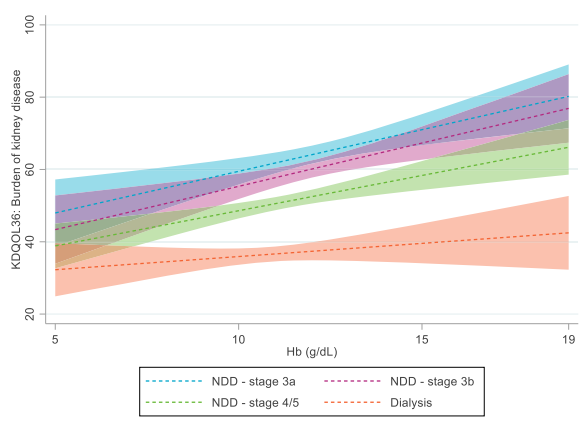

(b) KDQOL-36 SF-12 MCS

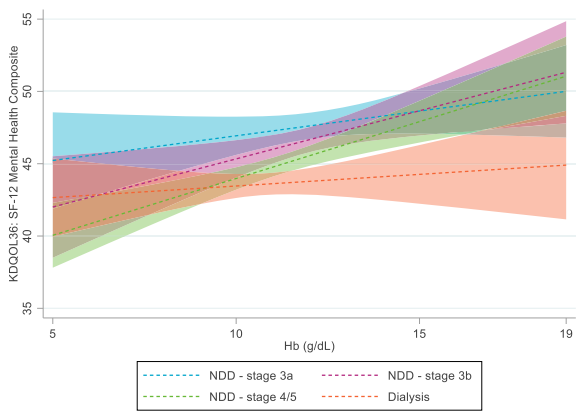

(d) KDQOL-36 effects of kidney disease ${ }^{c}$

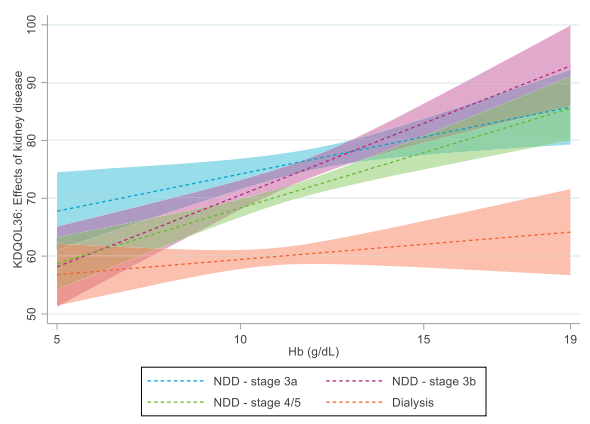

Fig. 4 Regression analyses. ${ }^{a}{ }^{a}$ These figures use regression models to show how the outcome changes with changing Hb with all other covariates set to their mean values. Predictive margins of current stage with 95\% Cls are shown separately for each CKD stage ${ }^{b}$ Symptoms and problems with kidney disease subscale. 'Effects of kidney disease on daily life subscale. ${ }^{d}$ Burden of kidney disease subscale. Cl, confidence interval; Hb, hemoglobin; NDD, non-dialysis dependent

explained by low patient numbers in this group as well as the limited sensitivity of the KDQOL-36 for common consequences of anemia specifically (fatigue, dizziness, decreased vitality, etc.).

In line with our findings, a number of published studies have reported CKD severity-linked impairment of HRQoL assessed via the EQ-5D-3 L [38, 39] and KDQOL-36 [28, 40]. A number of published studies and a systematic literature review have also reported a correlation of $\mathrm{Hb}$ level and HRQoL in patients with CKD [19-21, 29, 41]. However, the correlations reported in these studies are mostly unadjusted for potential confounders and anemia definitions often lack the granularity to differentiate between various levels of severity. Yet these studies, as well as our survey, provide generally consistent evidence on the HRQoL deterioration which occurs with CKD progression and development of anemia.

Various studies have also shown treatment to increase $\mathrm{Hb}$ levels in patients with CKD to be associated with HRQoL improvements [42-45]. Improvements were observed in energy/fatigue, physical functioning, ability to work, social activity and cognitive function, although the methods and tools used to measure these changes were diverse across studies, limiting the ability to combine results. Surprisingly, a large, double-blind study of patients with NDD CKD, type 2 diabetes mellitus, and anemia showed only modest improvements in scores from the 


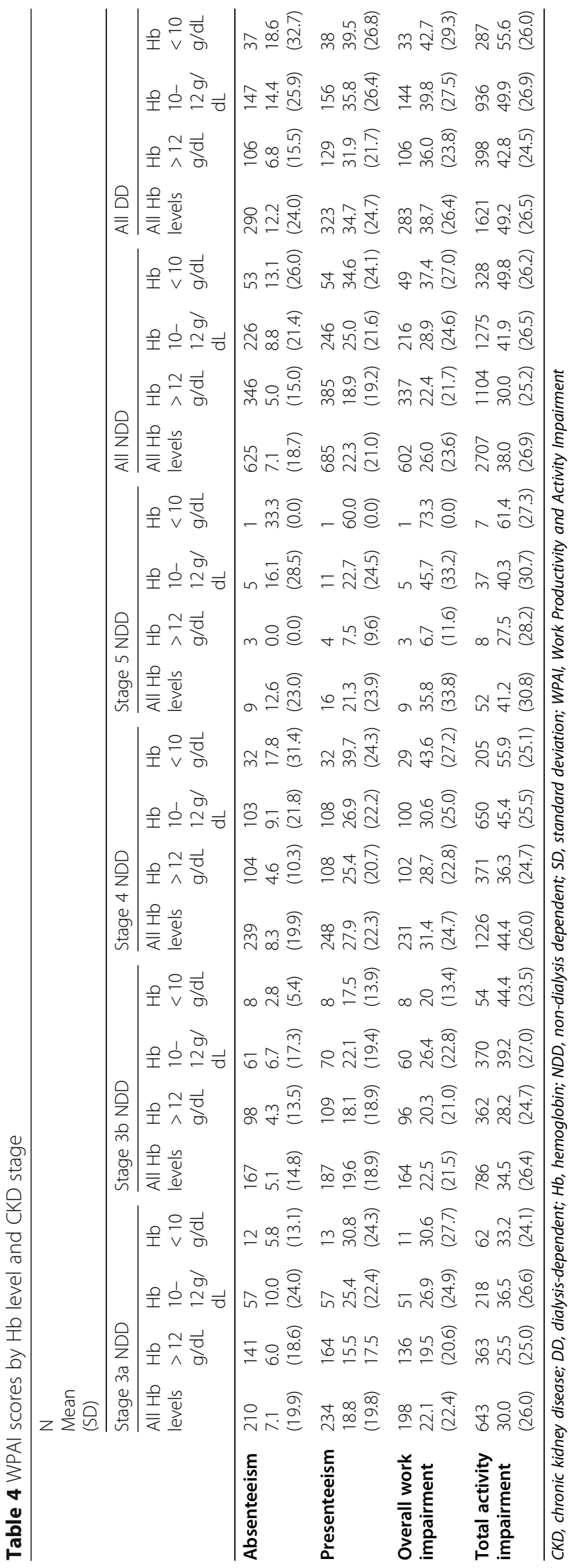


Functional Assessment of Cancer Therapy-Fatigue instrument, and no improved scores for the 36-Item ShortForm General Health Survey (SF-36) questionnaire, when patients received treatment for their anemia [46]. Additionally, a recent systematic review and meta-analysis concluded that there were no statistically or clinically significant differences between higher and lower $\mathrm{Hb}$ targets for HRQoL measured by SF-36 and Kidney Dialysis Questionnaire [47]. However, inherent to its focus on $\mathrm{Hb}$ target levels and specific HRQoL measures, potentially relevant studies were not considered due to the inability to combine results within a meta-analysis framework. Another complicating factor in studying HRQoL improvement in relation to $\mathrm{Hb}$ target levels are the risks observed in some studies associated with erythropoiesis-stimulating agents. Targeting an $\mathrm{Hb}$ level of $13.5 \mathrm{~g} / \mathrm{dL}$ with these agents has been shown to be associated with an increased risk of adverse events compared with a target of $11.3 \mathrm{~g} / \mathrm{dL}$ [48]. Limited improvement in HRQoL in some studies may also reflect baseline levels of HRQoL and/or $\mathrm{Hb}$ which were not low enough for improvements to be observed. An analysis of the response to treatment for anemia in two phase 2 studies of patients with NDD and DD CKD showed greater improvements in HRQoL in patients with lower baseline $\mathrm{Hb}$ levels [49]. Overall, the diversity in methods as well as results across studies still leaves important questions regarding anemia treatment and HRQoL unanswered.

Some limitations of this survey must be noted. As PRFs were completed for the next 12 consecutively consulting patients with CKD, the sample collected was pseudo-random, rather than a truly random sample. However, we did not identify any indications of systematic differences between our survey population and CKD populations that have been described elsewhere, and therefore we do not expect this to impact our findings and conclusions. Like all studies of this nature, the methodology relies on accurate reporting by physicians and patients. $\mathrm{Hb}$ levels reported for some patients were very low (two patients had $\mathrm{Hb}<4 \mathrm{~g} / \mathrm{dL}$ and 11 had $\mathrm{Hb}$ in the range 4.0 to $4.8 \mathrm{~g} / \mathrm{dL}$ ); these might have resulted from health issues, such as blood loss, unrelated to CKD, but some might have resulted from transcription errors in recording Hb levels in the PRF. It must also be noted that the observational and cross-sectional nature of this survey limits our abilities to assess causality between exposures and outcomes of interest. Therefore, the results from this survey can only be interpreted as associative. Also, patients who had previously received a kidney transplantation were not included in our analysis, thus it was not possible to evaluate the effect of anemia on HRQoL in this subpopulation of CKD patients. Different types of anemia treatment in participating patients were reported across the geographical regions. However, due to the study design no longitudinal comparisons between these were possible. Finally, as this analysis included only patients who had completed a PSC, it is possible that the results might not be generalizable to the broader CKD population, as patients might have been less likely to provide data if they were seriously ill with very poor HRQoL. Whilst acknowledging these limitations, this survey presents one of the largest and richest samples of CKD patients and their HRQoL to date, allowing for a comprehensive description of QoL estimates by $\mathrm{Hb}$ level and CKD stage, based on a variety of PRO outcome scales and across geographies. These unique aspects of our survey have advanced our understanding of how both CKD and anemia impact patients' well-being. Further research exploring HRQoL in patients with CKD receiving treatment to increase $\mathrm{Hb}$ levels would provide interesting insights, and could confirm if HRQoL can be maintained or improved through adequate intervention. Given the markedly reduced HRQoL values demonstrated in this survey, such intervention could potentially have very meaningful impact on patients' daily lives.

\section{Conclusions}

In conclusion, this multinational analysis confirmed a clear and consistent association between the presence of anemia and poorer HRQoL, which was particularly apparent in NDD patients. In addition, a correlation was shown between the presence of anemia and lower productivity, which was observed across all CKD patients irrespective of CKD stage. While aiming for optimal management of patients with CKD, it is clearly important to monitor $\mathrm{Hb}$ levels and be aware of the link between anemia and patients' overall wellbeing.

\section{Supplementary information}

Supplementary information accompanies this paper at https://doi.org/10. 1186/s12882-020-01746-4.

Additional file 1. Table 1 EQ-5D-3 L utility index and VAS scores by geographical region, $\mathrm{Hb}$ level and CKD stage.

Additional file 2. Table 2 KDQOL-36, SF-12 PCS and MCS scores by geographical region, $\mathrm{Hb}$ level and CKD stage.

Additional file 3 Fig. 1 The three main phases of a Disease Specific Programme (DSP). Figure 2 Distribution of current $\mathrm{Hb}$ levels.

\section{Abbreviations}

BMI: body mass index; CKD: chronic kidney disease; DD: dialysis-dependent; DSP: Disease Specific Programmes ${ }^{\mathrm{TM}}$; eGFR: estimated glomerular filtration rate; EQ-5D-3 L: EuroQol 5-Dimension 3-level; Hb: hemoglobin;

HRQoL: health-related quality of life; KDQOL-36: Kidney Disease Quality of Life Instrument; MCS: SF-12 Mental Component Summary; NDD: non-dialysis dependent; PCS: SF-12 Physical Component Summary; PRF: patient record forms; PRO: patient-reported outcomes; PSC: patient self-completion;

SD: standard deviation; SF 36: 36-Item Short-Form General Health Survey; SF12: 12-Item Short Form Health Survey; VAS: visual analog scale; WPAI: Work Productivity and Activity Impairment 


\section{Acknowledgements}

Medical writing support under the guidance of the authors was provided by Carole Evans, PhD on behalf of Adelphi Real World, and was funded by AstraZeneca, in accordance with Good Publication Practice (GPP3) guidelines (Ann Intern Med 2015;163:461-464).

\section{Authors' contributions}

$\mathrm{HvH}$ participated in the conception and design of the survey, interpretation of the data, and in manuscript writing and revision of drafts. JJ and RM participated in the conception and design of the survey and acquisition of data, analysed and interpreted the data, and participated in manuscript writing and revision of drafts. BS participated in the interpretation of the data, and in manuscript writing and revision of drafts. GM participated in analysing the data and reviewed the manuscript. All authors have reviewed the manuscript for critically important intellectual content; have given final approval of the version to be published and agree to be accountable for all aspects of the work in ensuring that questions related to the accuracy or integrity of any part of the work are appropriately investigated and resolved.

\section{Funding}

Funding for this project was provided by AstraZeneca. HvH is an employee of AstraZeneca; participated in the conception and design of the survey, interpretation of the data, and in manuscript writing and revision of drafts.

\section{Availability of data and materials}

All data supporting the survey is the intellectual property of Adelphi Real World and can be made available upon request (james.

jackson@adelphigroup.com).

The WPAI questionnaire used in our study can be found here: http://www. reillyassociates.net/WPAI_General.html.

\section{Ethics approval and consent to participate}

The survey was conducted as a market research survey adhering to the ICC/ ESOMAR International code on market and social research [50] and the European Pharmaceutical Marketing Research Association guidelines [51], and in full accordance with relevant legislation at the time of data collection including the US Health Insurance Portability and Accountability Act 1996 [52] and Health Information Technology for Economic and Clinical Health Act legislation [53]. Therefore, ethics committee approval was not required. Prior to volunteering to complete a questionnaire, all patients were asked to provide written informed consent. The survey instructions describe the purpose of the survey, why the respondent had been selected and who might have access to the aggregated and anonymized dataset compiled.

\section{Consent for publication}

Not applicable.

\section{Competing interests}

$\mathrm{HvH}$ is employed by AstraZeneca. JJ, RM and GM are employed by Adelphi Real World and declare no additional competing interests. BS reports research grants and/ or consultation fees from AstraZeneca, Akebia, Bayer, GSK, and Reata.

\section{Author details}

'AstraZeneca, Gothenburg, Sweden. ${ }^{2}$ Adelphi Real World, Bollington, UK. ${ }^{3}$ Division of Nephrology, New York Presbyterian Queens, Flushing, NY, USA.

Received: 11 July 2019 Accepted: 27 February 2020

Published online: 07 March 2020

\section{References}

1. Hill NR, Fatoba ST, Oke JL, Hirst JA, et al. Global prevalence of chronic kidney disease - a systematic review and meta-analysis. PLoS One. 2016;11: e0158765.

2. Trifirò G, Sultana J, Giorgianni F, Ingrasciotta Y, et al. Chronic kidney disease requiring healthcare services: a new approach to evaluate epidemiology of renal disease. Biomed Res Int. 2014;2014:268362.

3. Xue C, Ye XD, Li W, Peng Q, et al. Prevalence of chronic kidney disease in Jing adults in China: a village-based study. Clin Nephrol. 2013;79:50-6.

4. Zhang L, Zhang P, Wang F, Zuo L, et al. Prevalence and factors associated with CKD: a population study from Beijing. Am J Kidney Dis. 2008;51:373-84.
5. Campbell D, Weir MR. Defining, treating, and understanding chronic kidney disease--a complex disorder. J Clin Hypertens (Greenwich). 2015;17:514-27.

6. Fishbane S, Spinowitz B. Update on Anemia in ESRD and earlier stages of CKD: Core curriculum 2018. Am J Kidney Dis. 2018;71:423-35.

7. US National Library of Medicine. Anemia. Available at: https://medlineplus. gov/anemia.html. Accessed 18 Mar 2019.

8. KDIGO. KDIGO 2012 Clinical Practice Guideline for the Evaluation and Management of Chronic Kidney Disease 2012.Available at: https://kdigo.org/ guidelines/ckd-evaluation-and-management/.

9. Haase VH. Mechanisms of hypoxia responses in renal tissue. J Am Soc Nephrol. 2013;24:537-41.

10. Babitt JL, Lin HY. Mechanisms of anemia in CKD. J Am Soc Nephrol. 2012;23: $1631-4$.

11. Xu Y, Peng H, Ke B. a-klotho and anemia in patients with chronic kidney disease patients: A new perspective. Exp Ther Med. 2017;14:5691-5.

12. Astor BC, Muntner P, Levin A, Eustace JA, Coresh J. Association of kidney function with anemia: the third National Health and nutrition examination survey (1988-1994). Arch Intern Med. 2002;162:1401-8.

13. Li S, Foley RN, Collins AJ. Anemia and cardiovascular disease, hospitalization, end stage renal disease, and death in older patients with chronic kidney disease. Int Urol Nephrol. 2005;37:395-402.

14. Locatelli F, Pisoni RL, Combe C, Bommer J, et al. Anaemia in haemodialysis patients of five European countries: association with morbidity and mortality in the Dialysis outcomes and practice patterns study (DOPPS). Nephrol Dial Transplant. 2004;19:121-32.

15. McCullough PA, Lepor NE. The deadly triangle of anemia, renal insufficiency, and cardiovascular disease: implications for prognosis and treatment. Rev Cardiovasc Med. 2005;6:1-10

16. McFarlane SI, Salifu MO, Makaryus J, Sowers JR. Anemia and cardiovascular disease in diabetic nephropathy. Curr Diab Rep. 2006;6:213-8.

17. Stauffer ME, Fan T. Prevalence of anemia in chronic kidney disease in the United States. PLoS One. 2014;9:e84943.

18. Chen $\mathrm{Y}$, Qin $\mathrm{M}$, Zheng J, Yan $\mathrm{H}$, et al. Hemoglobin discriminates stages of chronic kidney disease in elderly patients. Exp Ther Med. 2015;10:567-71.

19. Soni RK, Weisbord SD, Unruh ML. Health-related quality of life outcomes in chronic kidney disease. Curr Opin Nephrol Hypertens. 2010;19:153-9.

20. Lefebvre P, Vekeman F, Sarokhan B, Enny C, et al. Relationship between hemoglobin level and quality of life in anemic patients with chronic kidney disease receiving epoetin alfa. Curr Med Res Opin. 2006;22:1929-37.

21. Eriksson D, Goldsmith D, Teitsson S, Jackson J, van Nooten F. Cross-sectional survey in CKD patients across Europe describing the association between quality of life and anaemia. BMC Nephrol. 2016;17:97.

22. Covic A, Jackson J, Hadfield A, Pike J, Siriopol D. Real-world impact of cardiovascular disease and Anemia on quality of life and productivity in patients with non-Dialysis-dependent chronic kidney disease. Adv Ther. 2017;34:1662-72.

23. Anderson P, Benford M, Harris N, Karavali M, Piercy J. Real-world physician and patient behaviour across countries: disease-specific Programmes - a means to understand. Curr Med Res Opin. 2008;24:3063-72.

24. Devlin NJ, Brooks R. EQ-5D and the EuroQol group: past, present and future. Appl Health Econ Health Policy. 2017;15:127-37.

25. Brooks R. EuroQol: the current state of play. Health Policy. 1996;37:53-72.

26. Rabin R, de Charro F. EQ-5D: a measure of health status from the EuroQol group. Ann Med. 2001;33:337-43.

27. Szende A, Oppe M, Devlin N. EQ-5D value sets: inventory, comparative review and user guide. Netherlands: Springer; 2007.

28. Gorodetskaya I, Zenios S, McCulloch CE, Bostrom A, et al. Health-related quality of life and estimates of utility in chronic kidney disease. Kidney Int. 2005:68:2801-8.

29. Mujais SK, Story K, Brouillette J, Takano T, Soroka S, Franek C, et al. Healthrelated quality of life in CKD patients: correlates and evolution over time. Clin J Am Soc Nephrol. 2009;4:1293-301.

30. Gibbons E, Fitzpatrick R. A structured review of patient-reported outcome measures for people with chronic kidney disease. Report to the Department of Health and NHS Kidney Care, 2010. 2010. Epub 2010.

31. Porter AC, Lash JP, Xie D, Pan Q, DeLuca J, Kanthety R, et al. CRIC study investigators: predictors and outcomes of health-related quality of life in adults with CKD. Clin J Am Soc Nephrol. 2016;11:1154-62.

32. Hays RD, Kallich JD, Mapes DL, Coons SJ, Carter WB. Development of the kidney disease quality of life (KDQOL) instrument. Qual Life Res. 1994;3:329-38. 
33. Peipert JD, Bentler PM, Klicko K, Hays RD. Psychometric properties of the kidney disease quality of life 36-item short-form survey (KDQOL-36) in the United States. Am J Kidney Dis. 2018;71:461-8.

34. Reilly Associates. WPAl references. 2015. Available at: http://www. reillyassociates.net/WPAl_References.html. Accessed 19 Mar 2019.

35. Reilly MC, Zbrozek AS, Dukes EM. The validity and reproducibility of a work productivity and activity impairment instrument. Pharmacoeconomics. 1993; 4:353-65.

36. Reilly Associates. WPAl scoring. 2002. Available at: http://www reillyassociates.net/WPAl_Scoring.html. Accessed 19 Mar 2019.

37. StataCorp. Stata statistical software: release 14. College Station, TX: StataCorp LP; 2015.

38. Tajima R, Kondo M, Kai H, Saito C, et al. Measurement of health-related quality of life in patients with chronic kidney disease in Japan with EuroQol (EQ-5D). Clin Exp Nephrol. 2010;14:340-8.

39. Park Jl, Baek H, Jung HH. CKD and health-related quality of life: the Korea National Health and nutrition examination survey. Am J Kidney Dis. 2016;67: 851-60.

40. Peng Z, Wang J, Yuan Q, Xiao X, et al. Clinical features and CKD-related quality of life in patients with CKD G3a and CKD G3b in China: results from the Chinese cohort study of chronic kidney disease (C-STRIDE). BMC Nephrol. 2017:18:311.

41. Farag YM, Keithi-Reddy SR, Mittal BV, Surana SP, et al. Anemia, inflammation and health-related quality of life in chronic kidney disease patients. Clin Nephrol. 2011;75:524-33.

42. Cody JD, Hodson EM. Recombinant human erythropoietin versus placebo or no treatment for the anaemia of chronic kidney disease in people not requiring dialysis. Cochrane Database Syst Rev. 2016;1:CD003266.

43. Drüeke TB, Locatelli F, Clyne N, Eckardt KU, et al. CREATE Investigators. Normalization of hemoglobin level in patients with chronic kidney disease and anemia. N Engl J Med. 2006;355:2071-84.

44. Revicki DA, Brown RE, Feeny DH, Henry D, et al. Health-related quality of life associated with recombinant human erythropoietin therapy for predialysis chronic renal disease patients. Am J Kidney Dis. 1995;25:548-54.

45. Ross SD, Fahrbach K, Frame D, Scheye R, et al. The effect of anemia treatment on selected health-related quality-of-life domains: a systematic review. Clin Ther. 2003:25:1786-805.

46. Pfeffer MA, Burdmann EA, Chen CY, Cooper ME, et al. TREAT Investigators. A trial of darbepoetin alfa in type 2 diabetes and chronic kidney disease. N Engl J Med. 2009;361:2019-32.

47. Collister D, Komenda P, Hiebert B, Gunasekara R, et al. The effect of erythropoietin-stimulating agents on health-related quality of life in Anemia of chronic kidney disease: a systematic review and meta-analysis. Ann Intern Med. 2016:164:472-8.

48. Singh AK, Szczech L, Tang KL, Barnhart $\mathrm{H}$, et al. CHOIR Investigators. Correction of anemia with epoetin alfa in chronic kidney disease. N Engl J Med. 2006;355:2085-98.

49. Szczech L, Hemmerich S, Besarab A, Saikali KG, et al. Anemia Correction with Roxadustat Improves Health-Related Quality of Life (HRQOL) in Chronic Kidney Disease (CKD) Patients in Phase 2 Studies. J Am Soc Nephrol 2015; 26. Abstract \#TH-ORO39.

50. European Society for Opinion and Marketing Research (ESOMAR), International Code on Market, Opinion and Social Research and Data Analytics. 2016. Available from https:/www.esomar.org/what-we-do/codeguidelines.

51. European Pharmaceutical Market Research Association (EphMRA) Code of Conduct. 2018. Available from http://www.ephmra.org/standards/code-ofconduct/.

52. US Department of Health and Human Services. Summary of the HIPAA Privacy Rule. 2003. Available from http://www.hhs.gov/sites/default/files/ privacysummary.pdf. Accessed 7 Aug 2019.

53. Health Information Technology. Health Information Technology Act. Available from https://www.healthit.gov/sites/default/files/hitech_act_ excerpt_from_arra_with_index.pdf. Accessed 7 Aug 2019.

\section{Publisher's Note}

Springer Nature remains neutral with regard to jurisdictional claims in published maps and institutional affiliations.

\section{Ready to submit your research? Choose BMC and benefit from:}

- fast, convenient online submission

- thorough peer review by experienced researchers in your field

- rapid publication on acceptance

- support for research data, including large and complex data types

- gold Open Access which fosters wider collaboration and increased citations

- maximum visibility for your research: over $100 \mathrm{M}$ website views per year

At $\mathrm{BMC}$, research is always in progress.

Learn more biomedcentral.com/submissions 